\title{
The Association Between Helicobacter pylori Infection and Rosacea
}

\author{
Parviz Saleh, ${ }^{1,2}$ Mohammad Naghavi-Behzad, ${ }^{3}$ Sara Babapour, ${ }^{3}$ and Reza Piri, ${ }^{4,}$ \\ ${ }^{1}$ Research Center for Infectious Diseases \& Tropical Medicine, Infectious and Tropical Diseases Department, Tabriz University of Medical Sciences, Tabriz, IR Iran \\ ${ }^{2}$ Chronic Kidney Diseases Research Center, Infectious and Tropical Diseases Department, Tabriz University of Medical Sciences, Tabriz, IR Iran \\ ${ }^{3}$ Student's Research Committee, Tabriz University of Medical Sciences, Tabriz, IR Iran \\ ${ }^{4}$ Medical Philosophy and History Research Center, Tabriz University of Medical Sciences, Tabriz, IR Iran \\ "Corresponding author: Reza Piri, M.D, Medical Philosophy and History Research Center, Tabriz University of Medical Sciences, Tabriz, IR Iran. Tel: +98-413345372, Fax: \\ +98-4133343359, E-mail: dr.reza.piri@gmail.com
}

Received 2016 December 04; Revised 2017 July 07; Accepted 2017 September 22.

\begin{abstract}
Background: Helicobacter pylori (H. pylori) is one the most infectious microorganism of human disease found in half of the world's population. Despite intense investigations into the spread of rosacea, the precise etiology remains unclear. There are theories, which suggest $H$. pylori as a predisposing factor for the occurrence. This study aimed at determining the prevalence of $H$. pylori in patients with rosacea.

Methods: This analytical-descriptive study was conducted on patients with rosacea disease attending Tabriz University of Medical Sciences Dermatology Clinics from October 2011 to January 2011. Patients, who were 18- to 65-year-olds with confirmed rosacea diagnosis, were included in the study. All patients were referred to a dermatologist and the severity of rosacea was categorized in 3 grades of mild, moderate and severe. Then H. pylori infection was investigated using H. pylori stool antigen. P values of less than 0.05 were considered statistically significant.

Results: Out of 63 patients with rosacea, 35 patients (55.55\%) were male and 28 patients (44.44\%) were female. Based on the rosacea categorization, 11 (17.46\%), 32 (50.79\%), and 20 (31.74\%) patients had respectively severe, moderate, and mild rosacea. There was no statistical significant difference regarding age and gender between different severities $(\mathrm{P}=0.39)$. Forty patients $(63.4 \%)$ out of all 63 were positive for $H$. pylori on stool antigen examination. There was no statistically significant association between $H$. pylori infection and gender $(\mathrm{P}=0.87)$ or age $(\mathrm{P}=0.62)$. There was a statistically significant difference between patients with $H$. pylori negative and positive test results considering severity $(\mathrm{P}=0.013)$.

Conclusions: In conclusion, although no association between rosacea and $H$. pylori infection was seen, there was a significant association between $H$. pylori infection and cases of severe rosacea.
\end{abstract}

Keywords: Rosacea, Prevalence, Severity, Helicobacter pylori

\section{Background}

Helicobacterpylori are gram-negative spiral-shaped bacteria that colonize the gastric mucosa lining and tend to cause upper GI diseases (1). Although they can be present in $50 \%$ of the population worldwide, studies show that in developing countries, H. pylori infection is well over twice the population in developed countries (2). Some studies suggest that these bacteria can also be linked to nongastroenterological diseases, such as ischemic heart disease, idiopathic thrombocytopenic purpura, and iron deficiency anemia (3-9). Risks for the incidence depends on the environment and poor living conditions $(10,11)$. The risk is higher mostly due to low socioeconomics by the theory of "contagion through society" (12). Epidemiologic reviews show most infections occur during childhood (13). Birth in developing countries is correlated with higher rates of infection, specifically crowded living conditions and poor socioeconomics (14). It seems that these bacteria are typically transferred through same age groups in families, yet then to the other members (15). Recent evidences suggest the principle role for $H$. pylori in dermatological problems, including Reynaud, rosacea, and urticarial rosacea, which is a chronic skin condition with frequent episodic characteristics, such as flushing, skin erythema, papulopustules, and skin telangiectasias $(16,17)$.

Helicobacter pylori of the gastric mucosa being considered as a pathogenic factor for rosacea has been controversial. Many reports have been published on the prevalence of $H$. pylori infection among patients with rosacea $(11,18-23)$, which ranges from studies reporting prevalence of $100 \%$ to studies indicating no significant difference between healthy people and the rosacea group $(24,25)$. De- 
spite intense investigations on the spread of rosacea, the precise etiology remains unclear. There are some theories that suggest that $H$. pylori is a predisposing factor for occurrence; nevertheless, different results have been retrieved. Therefore, considering this controversy mentioned in the literature, in the present study, it was aimed to show the incidence of $H$. pylori infection in patients with Rosacea.

\section{Methods}

This analytical-descriptive study was conducted on patients with rosacea disease attending Tabriz University of Medical Sciences dermatology clinics from October 2011 to January 2011. Patients from age 18 to 65 years with confirmed rosacea diagnosis were included in the study. In the case of any other dermatologic problem, former $H$. pylori eradication treatment, allergies to omeprazole or clarithromycin, topical treatment of rosacea in the past 3 weeks, antibiotic therapy within the past 3 months, and history of hospitalization in the past 6 months, patients were excluded from the study. All included patients, were precisely examined by a dermatologist to estimate the severity of rosacea, and were categorized to 3 grades of mild, moderate, and severe, according to the classification method proposed before (Table 1)(26). All demographic information, such as age, gender, and marital status, was collected at patients' enrollment time.

\begin{tabular}{|c|c|}
\hline \multicolumn{2}{|c|}{ Classification } \\
\hline \multirow{3}{*}{ Mild } & 1. Intermittent redness on chin, hands, and nose \\
\hline & 2.Visibly broken blood vessels appearing on skin \\
\hline & $\begin{array}{l}\text { 3. Foreign body sensation in eyes in some cases, gritty sensation } \\
\text { and feeling irritated }\end{array}$ \\
\hline \multirow{4}{*}{ Moderate } & 1. Persistent redness on facial skin \\
\hline & 2. Macules appearing on skin, Acne-like breakouts \\
\hline & $\begin{array}{l}\text { 3. Skin begins to thicken, Visible broken blood vessels (spider } \\
\text { veins) }\end{array}$ \\
\hline & 4. Reddish eyes, bloodshot appearance \\
\hline \multirow{3}{*}{ Severe } & 1. Progressive skin redness \\
\hline & 2. Erythema swelling and nose edema \\
\hline & 3. Blurred vision, inflamed eyes and orbit \\
\hline
\end{tabular}

To assess Helicobacter pylori infection, an applicator stick of 4 to $5 \mathrm{~mm}$ of stool was transferred in a diluent vial, and was vortexed for 20 seconds. Then, 4 drops of the vial was dispensed in ImmunoCard STAT HpSA kit (Meridian Diagnostics, Inc., OH, USA); negative and positive results were interpreted based on the manufacturer's recommendation. Statistical analysis was performed by the
SPSS software package, version 16.0, for Windows (SPSS Inc., Chicago, USA). Quantitative data are presented as the mean \pm standard deviation (SD), while qualitative data are demonstrated as frequency and percentages (\%). Student ttest, Fischer's exact and Analysis of Variance (ANOVA) were used for analysis of data. P values of less than 0.05 were considered statistically significant.

\section{Results}

During 3 months, 63 patients were included in the study. Out of 63 patients with rosacea, 35 patients (55.55\%) were male and 28 patients (44.44\%) were female. The severity of rosacea among patients based on gender is shown in Table 2. The mean age of the patients was $36.46 \pm 9.28$ years old. Moreover, patients afflicted with severe forms were $39.9 \pm 10.53$ years of age, moderate forms had an average age of $35.93 \pm 10.00$ and those with the mild form were aged $35.4 \pm 7.04$ years. There was no statistical significant difference according to age, as listed formerly $(\mathrm{P}=$ 0.39). In addition, 40 patients (63.4\%) out of 63 were positive for H. pylori on stool antigen examination. Of all H. pylori positive patients, 24 patients (38.09\%) were male and 16 patients $(25.39 \%)$ were female. There was no statistically significant association between $H$. pylori infection and gen$\operatorname{der}(\mathrm{P}=0.87)$. The mean age in patients with $H$. pylori positive test results was $37.02 \pm 9.84$ years old and in those with negative test results, mean age was $35.47 \pm 8.28$ years old; no statistically significant difference was found between them $(\mathrm{P}=0.62)$. The severity and $H$. pylori antigen status are shown in Table 3; there was a statistically significant difference between patients with $H$. pylori negative and positive test results, considering severity $(\mathrm{P}=0.13)$. This difference indicated greater $H$. pylori positive results in severe cases and mild cases mostly had $H$. pylori negative test results. Figure 1 shows the $H$. pylori antigen status among patients categorized based on severity.

\begin{tabular}{lccc}
\hline \multicolumn{4}{l}{ Table 2. Severity of Rosacea Among Patients Based on Gender ${ }^{\mathrm{a}}$} \\
\hline & Female & Male & Total \\
\hline Severe & $7(11.11)$ & $4(6.34)$ & $11(17.46)$ \\
Moderate & $15(23.8)$ & $17(26.98)$ & $32(50.79)$ \\
Mild & $6(9.52)$ & $14(22.22)$ & $20(31.74)$ \\
Total & $28(44.44)$ & $35(55.55)$ & $63(100)$ \\
\hline
\end{tabular}

${ }^{\mathrm{a}}$ Values are expressed as No. (\%).

\section{Discussion}

Helicobacter pylori is one the most infectious microorganisms of human disease that is found in half of the 


\begin{tabular}{lcccc}
\hline Table 3. Severity of Rosacea Among Patients Based on H. pylori Status & & \\
\hline & Positive H. pylori & Negative H. pylori & Total & P Value \\
\hline Severe & $10(15.87)$ & $1(1.58)$ & $11(17.46)$ & 0.04 \\
Moderate & $22(23.8)$ & $10(15.87)$ & $32(50.79)$ & 0.43 \\
Mild & $8(12.69)$ & $12(19.04)$ & $20(31.74)$ & 0.01 \\
Total & $40(63.49)$ & $23(36.5)$ & $63(100)$ & \\
\hline
\end{tabular}

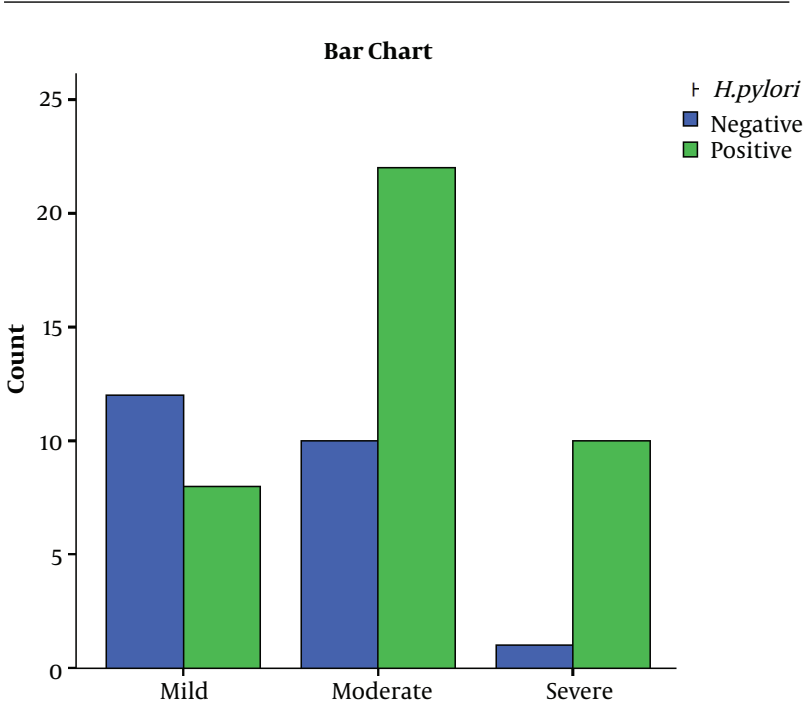

Figure 1. H. pylori Antigen Status Among Patients Categorized Based on Severity

world's population and proved to have participated in rosacea disease development. Rosacea is a chronic dermatological disease, with an unknown pathogenesis process, which has been the subject of many studies (27). Gastric infection with $H$. pylori is one of the proposed pathogenic sources of rosacea establishment (28), thus many researchers have tried to examine this association by trying to investigate the correlation between $H$. pylori infection and rosacea. This study aimed at showing the prevalence of $H$. pylori in patients with rosacea. In the present study, of 63 patients with rosacea, 40 (63.4\%) had positive $H$. pylori stool antigen. Prevalence of $H$. pylori varies worldwide depending on age. In a systematic review study by Eusebi et al. about epidemiology of H. pylori infection, it was concluded that in European and North American people, about one-third of adults are infected, yet in South America and Asia, the prevalence of H.pylori is often higher than 50\% and there was a low prevalence of infection in the younger generations, with the authors suggesting that it may lead to a decline of $H$. pylori prevalence in the coming decades (29). Studies conducted in Iran regarding the prevalence of H. pylori have reported rates from $50 \%$ to $90 \%$ (30-32); thus, the results presented among patients with rosacea reveals no significant difference with the general population.

In the present study, comparing the 2 groups of $H$. pylori antigen negative and positive reveals a statistically greater number of severe rosacea in patients with $H$. pylori positive results when compared with the $H$. pylori-negative group. Also, the number of mild cases of rosacea in $H$. pylori-negative group was statistically higher than cases of severe rosacea in H. pylori-positive group. This indicates a tendency for rosacea progression among $H$. pylori positive rosacea patients, although there were no differences between the 2 groups of $H$. pylori positive and negative when considering age and gender.

In a study by Argenziano et al. the probable association between serological evidence of $H$. pylori infection and rosacea was investigated and it was concluded that there is a significant association between rosacea and $H$. pylori infection (33). However, Abram et al. evaluated several suspected risk factors for rosacea and concluded that there was no statistically significant differences between rosacea patients and those of the control group (34); the present study revealed no association between $H$. pylori and rosacea, while it revealed an association between $H$. pylori infection and severe rosacea. In an interventional study by Utas et al. about effects of $H$. pylori eradication on rosacea, it was shown that although $H$. pylori eradication treatment does not treat rosacea completely, it decreases the severity (35); this study supports the current findings, which indicates existence of an association between $H$. pylori infection and severe rosacea.

In a study by Crawford et al., it was proposed that there is a high probability of repetitive $H$. pylori positive laboratory test results among people with severe rosacea disease (36); this is similar to the current study, where severe rosacea forms were associated with $H$. pylori positive antigen. In a study by Alborzi et al. investigating the prevalence of $H$. pylori infection in children, it was concluded that $H$. pylori prevalence decreases with age (37). Also in developing countries, this pattern of decline has been reported; in a study by Roosendaal et al. studying the prevalence of $H$. pylori from the first months of birth to adolescence rates of about $20 \%$ to $10 \%$ were reported. This is in contrast with the conclusions of the current study, although the sample 
population was chosen among patients with rosacea.

The controversy in this field could have many etiologies. Methods of how $H$. pylori are diagnosed is one factor, which is different amongst various studies; diagnosis methods include $H$. pylori stool antigen, serum $H$. pylori IgG, mucosal biopsy and C-Urea breath test $(38,39)$. These methods, besides sensitivity and specificity, have greater differences where invasiveness and financial aspects are counted, thus each researcher may choose a method based on the circumstances, while unknowingly creating a bias. Another factor expanding this controversy is population selection; besides significant differences in $H$. pylori prevalence based on location and racial aspects $(40,41)$, most of the populations are selected in a way that selection bias occurs when including patients attending clinical centers, while most of the patients with $H$. pylori infection are asymptomatic.

\subsection{Conclusions}

In conclusion, there is no association between rosacea and $H$. pylori infection, although there was a significant association between $H$. pylori infection and severe rosacea. The current study showed no difference between groups considering age and gender. Results of the present study could be an outline for further interventional and cohort studies, which could lead to a more precise conclusion. Further studies are encouraged with a larger population considering other probable confounding covariates.

\section{References}

1. Mobley HLT, Mendz GL, Hazell SL.National Library of Medicine. He licobacter pylori physiology and genetics. Washington, DC: ASM Press; 2001

2. Sutton P, Mitchell H. Helicobacter pylori in the 21st Century. 17. CABI; 2010.

3. Malfertheiner P, Megraud F, O'Morain C, Bazzoli F, El-Omar E, Graham $D$, et al. Current concepts in the management of Helicobacter pylori infection: the Maastricht III Consensus Report. Gut. 2007;56(6):772-81. doi: 10.1136/gut.2006.101634. [PubMed:17170018].

4. Gasbarrini A, Franceschi F, Gasbarrini G, Pola P. Extraintestinal pathology associated with Helicobacter infection. Eur J Gastroenterol Hepatol.1997;9(3):231-3. [PubMed: 9096420]

5. Tan HJ, Goh KL. Extragastrointestinal manifestations of Helicobacter pylori infection: facts or myth? A critical review. J Dig Dis. 2012;13(7):342-9. doi: 10.1111/j.1751-2980.2012.00599.x. [PubMed: 22713083]

6. Dufour C, Brisigotti M, Fabretti G, Luxardo P, Mori PG, Barabino A. Helicobacter pylori gastric infection and sideropenic refractory anemia. J Pediatr Gastroenterol Nutr. 1993;17(2):225-7. [PubMed: 8229554].

7. Taghavi Zenouz A, Mehdipour M, Heydarlou M, Gholizadeh N. Relationship between lichen planus and Helicobacter pylori infection. $J$ Dent Res Dent Clin Dent Prospects. 2010;4(1):17.

8. Ghotaslou R, Milani M, Akhi MT, Nahaei MR, Hasani A, Hejazi MS, et al. Diversity of Helicobacter Pylori cagA and vacA Genes and Its Relationship with Clinical Outcomes in Azerbaijan, Iran. Adv Pharm Bull. 2013;3(1):57-62. doi: 10.5681/apb.2013.010. [PubMed: 24312813].
9. Estakhri R, Somi MH, Rohbakhsh K, Vahedi A, Poorasghary B. The Effects of Helicobacter Pylori Eradication in Blood Level of Biochemical Parameters Related to Coronary Heart Diseases. Med J Tabriz Univ Med Sci Health Serv. 2013;35(5):6-11.

10. Wong BC, Lam SK, Wong WM, Chen JS, Zheng TT, Feng RE, et al. Helicobacter pylori eradication to prevent gastric cancer in a high-risk region of China: a randomized controlled trial. JAMA. 2004;291(2):18794. doi: 10.1001/jama.291.2.187. [PubMed:14722144].

11. Salehi MR, Aboei MS, Naghsh N, Hajisadeghi S, Ajami E. A comparison in prevalence of Helicobacter pylori in the gingival crevicular fluid from subjects with periodontitis and healthy individuals using polymerase chain reaction. JDent Res Dent Clin Dent Prospects. 2013;7(4):238.

12. Kramer AD, Guillory JE, Hancock JT. Experimental evidence of massive-scale emotional contagion through social networks. Proc Natl Acad Sci U S A. 2014;111(24):8788-90. doi: 10.1073/pnas.1320040111. [PubMed: 24889601].

13. Malaty HM, El-Kasabany A, Graham DY, Miller CC, Reddy SG, Srinivasan SR, et al. Age at acquisition of Helicobacter pylori infection: a followup study from infancy to adulthood. Lancet. 2002;359(9310):931-5. doi: 10.1016/S0140-6736(02)08025-X. [PubMed: 11918912].

14. Malaty HM, Logan ND, Graham DY, Ramchatesingh JE. Helicobacter pylori infection in preschool and school-aged minority children: ef fect of socioeconomic indicators and breast-feeding practices. Clin Infect Dis. 2001;32(10):1387-92. doi: 10.1086/320148. [PubMed: 11317237].

15. Irani S, Esfahani AM, Zerehpoush F. Detection of Helicobacter pylori in oral lesions. J Dent Res Dent Clin Dent Prospects. 2013;7(4):230.

16. Wedi B, Kapp A. Helicobacter pylori infection in skin diseases: a critical appraisal. Am J Clin Dermatol. 2002;3(4):273-82. [PubMed: 12010072].

17. Shiotani A, Okada K, Yanaoka K, Itoh H, Nishioka S, Sakurane M, et al Beneficial effect of Helicobacter pylori eradication in dermatologic diseases. Helicobacter. 2001;6(1):60-5. [PubMed: 11328367].

18. Zandi S, Shamsadini S, Zahedi MJ, Hyatbaksh M. Helicobacter pylori and rosacea. East Mediterr Health J. 2003;9(1-2):167-71. [PubMed: 15562747].

19. Hernando-Harder AC, Booken N, Goerdt S, Singer MV, Harder H. Helicobacter pylori infection and dermatologic diseases. Eur J Dermatol. 2009;19(5):431-44. doi: 10.1684/ejd.2009.0739. [PubMed: 19527988].

20. El-Khalawany M, Mahmoud A, Mosbeh AS, A. B. D. Alsalam F, Ghonaim $\mathrm{N}$, Abou-Bakr A. Role of Helicobacter pylori in common rosacea subtypes: a genotypic comparative study of Egyptian patients. J Dermatol. 2012;39(12):989-95. doi: 10.1111/j.1346-8138.2012.01675.x. [PubMed: 23039081].

21. Bhattarai S, Agrawal A, Rijal A, Majhi S, Pradhan B, Dhakal SS. The study of prevalence of Helicobacter pylori in patients with acne rosacea Kathmandu Univ Med J(KUMJ). 2012;10(40):49-52. [PubMed: 23575053].

22. Prelipcean CC, Mihai C, Gogălniceanu P, Mitrică D, Drug VL, Stanciu C. Extragastric manifestations of Helicobacter pylori infection. Revista medico-chirurgicala a Societatii de Medici si Naturalisti din Iasi. 2007;111(3):575-83.

23. Yousefi L, Ghotaslou R, Akhi MT, Asgharzadeh M, Nahaei MR, Rafeey M. Frequency of Helicobacter pylori blood-group antigen-binding adhesion 2 and sialic acid binding adhesion genes among dyspeptic patients in Tabriz, Iran. J Analyt Res Clin Med. 2015;3(2):71-6. doi 10.15171/jarcm.2015.011.

24. Dakovic Z, Vesic S, Vukovic J, Milenkovic S, Jankovic-Terzic K, Dukic S, et al. Ocular rosacea and treatment of symptomatic Helicobacter pylori infection: a case series. Acta dermatovenerologica Alpina, Pannonica, et Adriatica. 2007;16(2):83-6.

25. Mayr-Kanhauser S, Kranke B, Kaddu S, Mullegger RR. Resolution of granulomatous rosacea after eradication of Helicobacter pylori with clarithromycin, metronidazole and pantoprazole. Eur J Gastroenterol Hepatol. 2001;13(11):1379-83. [PubMed: 11692067].

26. Jansen T, Plewig G. Rosacea: classification and treatment. J R Soc Med. 1997;90(3):144-50. [PubMed: 9135612]. 
27. Odom R, Dahl M, Dover J, Draelos Z, Drake L, Macsai M, et al. Standard management options for rosacea, part 2: options according to subtype. Cutis. 2009;84(2):97-104. [PubMed: 19746768].

28. Szlachcic A. The link between Helicobacter pylori infection and rosacea. J Eur Acad Dermatol Venereol. 2002;16(4):328-33. [PubMed: 12224687].

29. Eusebi LH, Zagari RM, Bazzoli F. Epidemiology of Helicobacter pylori infection. Helicobacter. 2014;19 Suppl 1:1-5. doi: 10.1111/hel.12165. [PubMed: 25167938].

30. Milani M, Ghotaslou R, Akhi MT, Nahaei MR, Hasani A, Somi MH, et al. The status of antimicrobial resistance of Helicobacter pylori in Eastern Azerbaijan, Iran: comparative study according to demographics. J Infect Chemother. 2012;18(6):848-52. doi: 10.1007/s10156-012-04254. [PubMed: 22581031].

31. Mansour-Ghanaei F, Mashhour M, Joukar F, Sedigh M, Bagher-Zadeh AH, Jafarshad R. Prevalence of Helicobacter pylori infection among children in Rasht, Northern Iran. Middle East J Digest Dis. 2009;1(2):848

32. Saleh P, Naghavi-Behzad M, Herizchi H, Mokhtari F, Mirza-AghazadehAttari M, Piri R. Effects of Helicobacter pylori treatment on rosacea: A single-arm clinical trial study. J Dermatol. 2017;44(9):1033-7. doi 10.1111/1346-8138.13878. [PubMed: 28452093].

33. Argenziano G, Donnarumma G, Iovene MR, Arnese P, Baldassarre MA Baroni A. Incidence of anti-Helicobacter pylori and anti-CagA antibodies in rosacea patients. Int J Dermatol. 2003;42(8):601-4. [PubMed 12890101].

34. Abram K, Silm H, Maaroos HI, Oona M. Risk factors associated with rosacea. J Eur Acad Dermatol Venereol. 2010;24(5):565-71. doi 10.1111/j.1468-3083.2009.03472.x. [PubMed: 19874433].

35. Utas S, Ozbakir O, Turasan A, Utas C. Helicobacter pylori eradication treatment reduces the severity of rosacea. J Am Acad Dermatol. 1999;40(3):433-5. [PubMed: 10071314].

36. Crawford GH, Pelle MT, James WD. Rosacea: I. Etiology, pathogenesis, and subtype classification. JAm Acad Dermatol. 2004;51(3):327-41. quiz 342-4. doi:10.1016/j.jaad.2004.03.030. [PubMed: 15337973].

37. Alborzi A, Soltani J, Pourabbas B, Oboodi B, Haghighat M, Hayati $\mathrm{M}$, et al. Prevalence of Helicobacter pylori infection in children (south of Iran). Diagn Microbiol Infect Dis. 2006;54(4):259-61. doi: 10.1016/j.diagmicrobio.2005.10.012. [PubMed: 16466888].

38. Saleh P, Zarrintan A, Zeinal Zade AH, Piri R, Mohammadi S, NaghaviBehzad M. Efficiency of Helicobacter pylori Infection Treatment Protocol: Clarithromycin, Amoxicillin and Omeprazole. Arch Clin Infect Dis. 2012;8(1):14-7. doi: 10.5812/archcid.14408.

39. Kokkola A, Rautelin H, Puolakkainen P, Sipponen P, Farkkila M, Haapiainen R, et al. Diagnosis of Helicobacter pylori infection in patients with atrophic gastritis: comparison of histology, 13C-urea breath test, and serology. Scand J Gastroenterol. 2000;35(2):138-41. [PubMed: 10720110].

40. De Francesco V, Giorgio F, Hassan C, Manes G, Vannella L, Panella C, et al. Worldwide H. pylori antibiotic resistance: a systematic review.J Gastrointestin Liver Dis. 2010;19(4):409-14. [PubMed: 21188333].

41. Porras C, Nodora J, Sexton R, Ferreccio C, Jimenez S, Dominguez RL, et al. Epidemiology of Helicobacter pylori infection in six Latin American countries (SWOG Trial S0701). Cancer Causes Control. 2013;24(2):209-15. doi: 10.1007/s10552-012-0117-5. [PubMed: 23263777]. 